\title{
An evaluation of the artificial neural network based on the estimation of daily average global solar radiation in the city of Surabaya
}

\author{
Adi Kurniawan ${ }^{1}$, Anisa Harumwidiah ${ }^{2}$ \\ ${ }^{1}$ Department of Marine Engineering, Institut Teknologi Sepuluh Nopember, Indonesia \\ ${ }^{2}$ Study Program of Electric Technology, Universitas 17 Agustus 1945 Surabaya, Indonesia
}

\begin{tabular}{|c|c|}
\hline Article Info & ABSTRACT \\
\hline Article history: & The estimation of the daily average global solar radiation is important since it \\
\hline Received Oct 26, 2020 & $\begin{array}{l}\text { ncreases the cost efriciency of solar power plant, especially in developing } \\
\text { countries. Therefore, this study aims at developing a multi layer perceptron }\end{array}$ \\
\hline Revised May 28, 2021 & artificial neural network (ANN) to estimate the solar radiation in the city of \\
\hline Accepted Jun 11, 2021 & $\begin{array}{l}\text { Surabaya. To guide the study, seven (7) available meteorological parameters } \\
\text { and the number of the month was applied as the input of network. The ANN }\end{array}$ \\
\hline Keywords: & $\begin{array}{l}\text { was trained using five-years data of } 2011-2015 \text {. Furthermore, the model was } \\
\text { validated by calculating the mean average percentage error (MAPE) of the }\end{array}$ \\
\hline $\begin{array}{l}\text { Machine learning } \\
\text { Mean average percentage error } \\
\text { Mean squared error }\end{array}$ & $\begin{array}{l}\text { estimation for the years of } 2016-2019 \text {. The results confirm that the } \\
\text { aforementioned model is feasible to generate the estimation of daily average } \\
\text { global solar radiation in Surabaya, indicated by MAPE of less than } 15 \% \text { for all } \\
\text { testing years. }\end{array}$ \\
\hline
\end{tabular}

This is an open access article under the CC BY-SA license.

Weather parameter

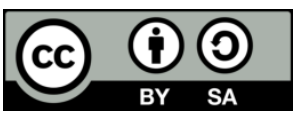

Corresponding Author:

Adi Kurniawan

Department of Marine Engineering

Institut Teknologi Sepuluh Nopember

Jalan Raya ITS, Keputih, Sukolilo, Surabaya 60111, Indonesia

Email: adi.kurniawan@ne.its.ac.id

\section{INTRODUCTION}

Surabaya, the second biggest city in Indonesia, is famous for its high temperature and humidity. It is also ranked second highest global solar radiation among the big cities with a daily average of $5.29 \mathrm{kWh} / \mathrm{m}^{2}$ [1]. However, this potential is yet to be utilized, as there is no big or even medium scale photovoltaic (PV) power plant in Surabaya. In Indonesia, only 152 MW PV has been installed by November 2019, which is less than $0.1 \%$ of $536 \mathrm{GW}$ potential [2]. Despite the recent continuous decrease in the price of the PV panel [3], [4] the total cost of PV power plant is quite expensive for developing countries such as Indonesia. Moreover, most of the equipment of the PV energy systems such as the panels and power electronic converters are not produced in Indonesia. Therefore, an efficient design and operation is required in order to increase the cost efficiency of the system [5].

The information of the availability of the global solar radiation holds a significant role in building efficient design and operation on PV energy systems [6]. The amount of daily average global solar radiation has been widely applied for various studies which includes investigating the feasibility of solar power plant [7] optimal sizing of the energy storage systems [8], [9] determination of the optimal tilt angle [10]-[12], and designing energy management system [13]. However, the data of measured solar radiation is limitedly available. Furthermore, some design processes demand the prediction of the future global solar radiationTherefore, the prediction or estimation of the global solar radiation is necessary [14], [15]. 
Numerous approaches have been proposed to estimate the amount of solar radiation on horizontal plane. Empirical models such as linear, quadratic, cubic, logarithmic, and exponential regression have been widely used since 1940's [16], [17]. Recent methods employ machine learning algorithm in the form of artificial neural network (ANN) [18]-[20], gradient boosting tree (GBT) [21], genetic programming (GP) [22], [23], and support vector machine [24], [25] among others. In comparison with other estimation method,multi-layer perceptron ANN is one of the most popular since it solves high non-linearity, complex, and time-varying problems [26] and it has also been proven to have higher accuracy [27], [28].

Various meteorological parameters were used as inputs for ANN to estimate the daily average global solar radiation. The choice of parameters includes the availability of the data, its effect to the estimation accuracy, and the thought of complexity or simplicity of the network. The common weather parameters used as the input includes sunshine duration, cloudiness, temperature, humidity, and wind speed. Other parameters besides meteorological data are position (latitude and longitude) and altitude of the city, as well as the number of month [29], [30].

This study aims to investigate the feasibility of the common multi layer perceptron ANN to estimate the daily average global solar radiation using Surabaya meteorological data. The analysis of the results will help generate recommendations to improve the accuracy of the estimation model. The contribution of this paper is to generate an ANN model to estimate the daily average solar radiation for Surabaya city using available meteorological data.

In section 2, the detail of the proposed method is explained. Meanwhile, the explanation of he comparison results between measured and estimated daily average solar radiation is presented in section 3 . The section 4 contains the conclusion of the findings in this research.

\section{RESEARCH METHOD}

The available weather parameters used as input for the neural network are minimum temperature $\left(T_{\min }\right)$, average temperature $\left(T_{a v g}\right)$, maximum temperature $\left(T_{\max }\right)$, average relative humidity $(R H)$, precipitation $(P r)$, sunshine duration $(S D)$, and average wind speed $(W S)$. These parameters were taken from the database of Indonesian Meteorological, Climatological, and Geophysical Agency (BMKG). The weather parameters of Surabaya are measured in Tanjung Perak Maritime Meteorology Station and are available as day-to-day metric and are, then converted into a daily average per month for the input of the network. The additional input data is the number of the month $(j)$, since the daily average solar radiation on each month may vary due to the rainy and dry season. The output of the network is the daily average global solar radiation on a horizontal surface $(G)$. The data were obtained from the NASA Power database, in the form of total solar radiation per day, it was then converted to the daily average amount for each month. The structure of the network is presented in Figure 1. Due to the minimum error during the training process, three numbers of neurons in hidden layers are selected.

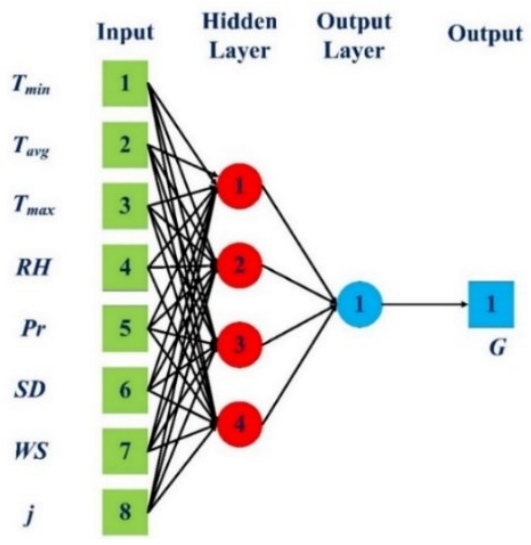

Figure 1. Configuration of ANN to predict the global solar radiation

The ANN was trained using an unfiltered 5-years data from January 2011 to December 2015. 60 samples of input-output correlation data were utilized for the training process. The training process to determine the appropriate weight value for each connection between neurons was carried out based on its convergence and stability speed according to the Levenberg-Marquardt method [30], in order to minimize errors defined as: 


$$
\mathrm{MSE}=\frac{1}{n} \sum_{k=1}^{n} e_{k}^{2}=\frac{1}{n} \sum_{k=1}^{n}\left(t_{k}-y_{k}\right)^{2}
$$

where $n$ is the total number of samples of the output parameter, $k$ is the index of the output samples, $e$ is the error of the output, $t$ is the target value of the output from the data, and $y$ is the output value obtained from the calculation of the ANN [31]-[33].

To evaluate the effectiveness of the trained ANN, a comparison is made between estimation and measured value for 2016-2019 data. The ANN is used to calculate the estimation of daily average global solar radiation per month by applying the weather parameters data of 2016-2019. The results were then compared with the actual global solar radiation from the NASA Power database for the same month of the same year with the statistical parameter calculated as the mean average percentage error (MAPE) for each year as follow:

$$
\mathrm{MAPE}=\frac{1}{12} \sum_{j=1}^{12}\left|\frac{G p_{j}-G m_{j}}{G m_{j}}\right| \times 100 \%
$$

where $j$ is the index of the month, $G p$ is the estimated value of the daily average solar radiation per month taken from the result of the ANN, and $G m$ is the measured value of the daily average solar radiation taken from NASA. The MAPE has been used in previous studies as a parameter to measure the accuracy of solar radiation estimation using ANN [28].

\section{RESULTS AND DISCUSSION}

The ANN training process shows a good correlation between the target from the data and the output of the ANN, indicated by a regression value of 0.967 as shown in Figure 2. It also indicates that the five years training data have a strong correlation between the inputs and the output. The graphical comparisons between the estimated and measured daily average global solar radiation per month for 2016-2019 years are shown in Figure 3 and it indicate that the estimation values tend to be lower than measured ones. The differences are especially larger during the peaks of dry season between July and October. In contrast, the highest similarity was observed in the peaks of rainy season between December and February. Given the large difference of daily average precipitation during dry $(1.89 \mathrm{~mm})$ and rainy season $(9.35 \mathrm{~mm})$ per year in $2011-2015$, the division of the ANN training for each season will improve the accuracy of the estimation.

The statistical results of MAPE for each year are presented in Table 1. The error is on the increase for the more recent year, this is as a result of the increase in the measured daily average solar radiation in Surabaya between 2016 and 2019. The measured values are $4.8 \mathrm{kWh} / \mathrm{m}^{2}$ in 2016, 4.98 in 2017, 5.3 in 2018, and 5.48 in 2019. Meanwhile, the input parameters are somewhat stable for each year. For example, in the same period, the average temperatures are $29.04,28.55,28.78$, and $29.02^{\circ} \mathrm{C}$ respectively.

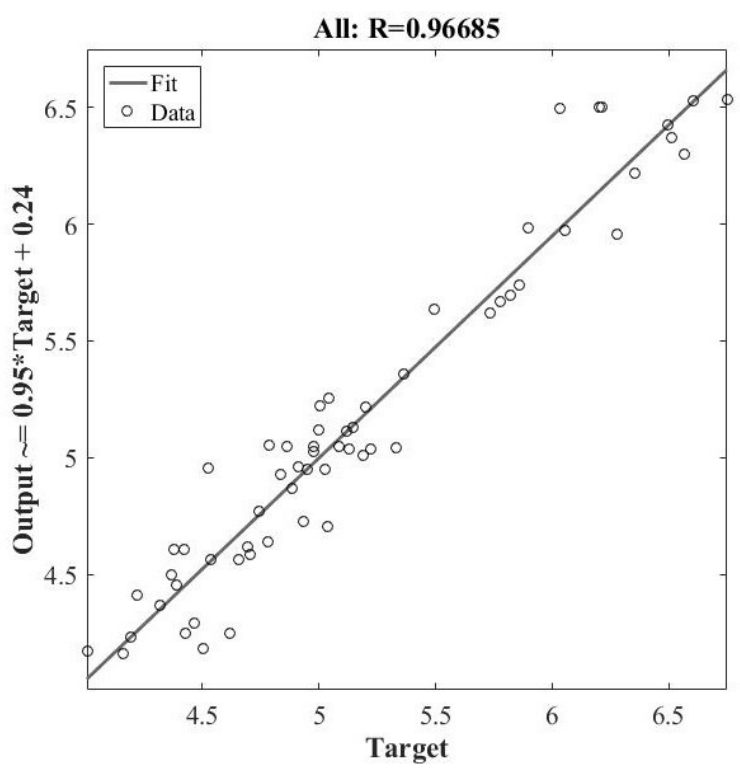

Figure 2 Graphics of regression between target and the output during the ANN training process 


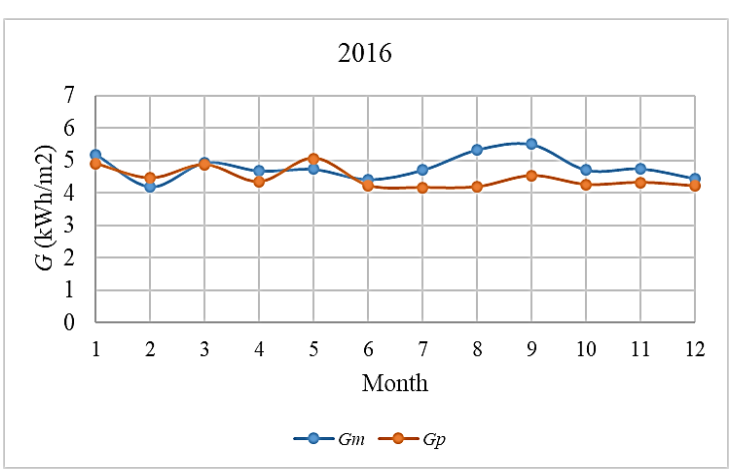

(a)

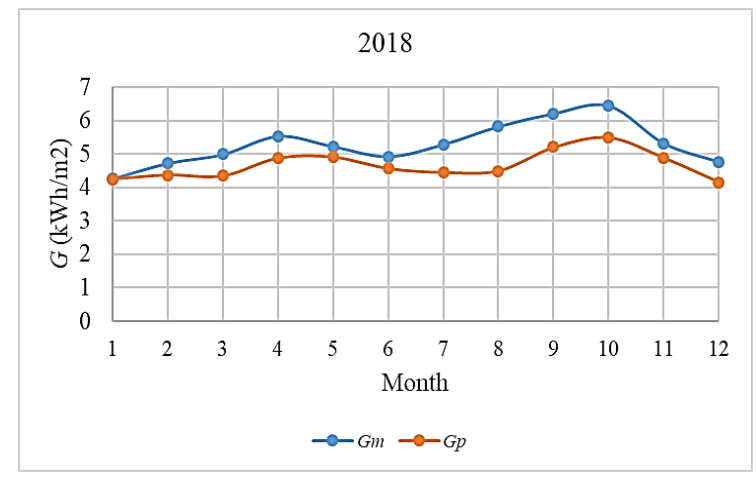

(c)

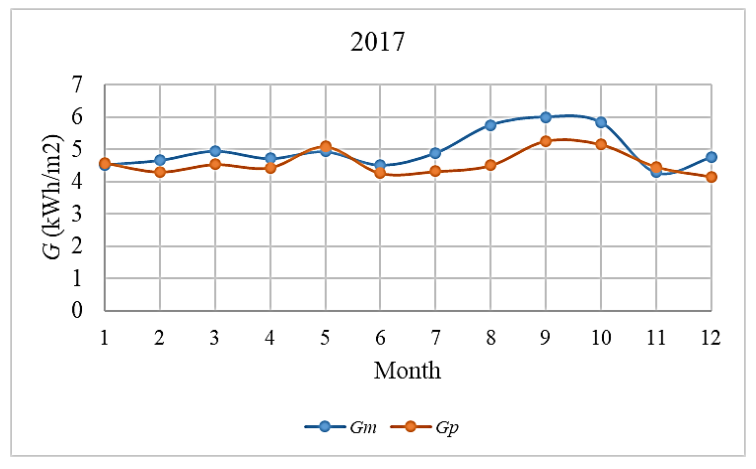

(b)

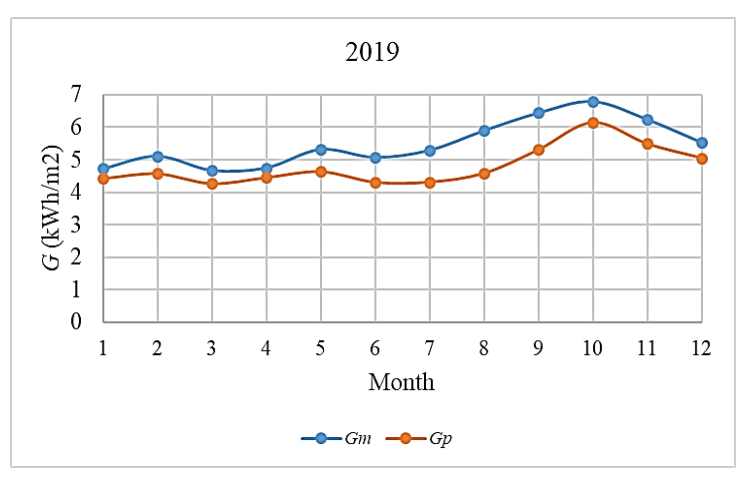

(d)

Figure 3. Graphical comparisons between measured and estimated daily average solar radiation per month for the year of; (a) 2016, (b) 2017, (c) 2018, and (d) 2019

Table 1. Statistical results of the daily average solar radiation estimation model for Surabaya

\begin{tabular}{cc}
\hline Year & MAPE (\%) \\
\hline 2016 & 8.77 \\
2017 & 8.82 \\
2018 & 11.38 \\
2019 & 12.41 \\
\hline
\end{tabular}

In order to evaluate the capability of the ANN model to estimate the daily average global solar radiation in Surabaya, one need to compare the MAPE acquired in this study with the results from the previous studies. The MAPE in this study is clearly higher than average of $6.89 \%$ achieved for the cities in India [34], $5.47 \%$ of Japan [35], 4.49\% of Saudi Arabia [20], 5.21\% of Iran [36], and 5.38\% of Malaysia [27]. However, the MAPE results for 2016 and 2017 in this study are classified under high accurate prediction, while the results for 2018 and 2019 are classified as good estimation according to Lewis classification [34]. The value of MAPE in this study also lower than similar study in Fez, Morocco, in which the best achieved MAPE is $21.77 \%$ [37].

\section{CONCLUSION}

The results from this study indicate that the estimated value of the solar radiation from the ANN can approach the value of the measured one, as proven by MAPE (less than 20). Therefore, the common multi layer perceptron ANN estimator model with the available meteorological data is reliable to estimate the daily average global solar radiation for the city of Surabaya. However, the improvement of the accuracy of the estimator is highly possible when two separate ANN are trained and applied separately for dry and rainy season. The increase in errors over the past year also suggests that a limitation in the number of previous years to be used for the training process is required to estimate solar radiation over a given year. 


\section{FUTURE WORK}

In the next step, the accuracy improvement of the ANN estimator needs to be designed by applying classification method for dry and rainy season. Further, the ANN estimator with location as the inputs will also designed to be able to estimate the daily average solar radiation in all area in Indonesia.

\section{ACKNOWLEDGEMENTS}

This study is financially supported by Institut Teknologi Sepuluh Nopember by the scheme of "Penelitian Dana Departemen" no. 1732/PKS/ITS/2020. The researchers are thankful to the Indonesian Meteorological, Climatological, and Geophysical Agency (BMKG) for providing the meteorological data used in this research.

\section{REFERENCES}

[1] The World Bank Group, Solar resource and photovoltaic potential of Indonesia, 2017 [Online]. Available: https://documents.worldbank.org/en/publication/documents-reports/documentdetail/729411496240730378/solarresource-and-photovoltaic-potential-of-indonesia

[2] A. P. Tampubolon, A. Alfath, H. Damayanti, I. Marciano, and P. Simamora, "Indonesia clean energy outlook: Tracking progress and review of clean energy development in Indonesia," Jakarta, Indonesia: Insitute for Essential Services Reform, 2019.

[3] S. Motahhir, A. Chalh, A. El Ghzizal, and A. Derouich, "Development of a low-cost PV system using an improved INC algorithm and a PV panel proteus model," Journal of Cleaner Production, vol. 204, pp. 355-365, 2018, doi: $10.1016 /$ j.jclepro.2018.08.246.

[4] K. Branker, M. J. M. Pathak, and J. M. Pearce, "A review of solar photovoltaic levelized cost of electricity," Renewable and Sustainable Energy Reviews, vol. 15, no. 9, pp. 4470-4482, 2011, doi: 10.1016/j.rser.2011.07.104.

[5] A. Askarzadeh, "Solution for sizing a PV/Diesel HPGS for Isolated sites," IET Renewable Power Generation, vol. 11, no. 1, pp. 143-151, 2017, doi: 10.1049/iet-rpg.2016.0319.

[6] R. Ihaddadene, N. Ihaddadene, M. Salemi, and A. Beghidja, "New model to estimate monthly global solar radiation from air temperature in Algeria," 2018 9th International Renewable Energy Congress (IREC), 2018, pp. 1-6, doi: 10.1109/IREC.2018.8362492.

[7] E. A. Ahmed and M. E. Adam, "Estimate of global solar radiation by using artificial neural network in Qena, Upper Egypt," Journal of Clean Energy Technologies, vol. 1, no. 2, pp. 148-150, 2013, doi: 10.7763/JOCET.2013.V1.35.

[8] C. Yao, M. Chen, and Y. Hong, "Novel adaptive multi-clustering algorithm-based optimal ESS sizing in ship power system considering uncertainty," in IEEE Transactions on Power Systems, vol. 33, no. 1, pp. 307-316, Jan. 2018, doi: 10.1109/TPWRS.2017.2695339.

[9] A. N. Azmi, N. Salim, and A. Khamis, "Analysis of an energy storage sizing for grid-connected photovoltaic system," Indonesian Journal of Electrical Engineering and Computer Science, vol. 16, no. 1, pp. 17-24, 2019, doi: 10.11591/ijeecs.v16.i1.pp17-24.

[10] S. Akhlaghi, H. Sangrody, M. Sarailoo, and M. Rezaeiahari, "Efficient operation of residential solar panels with determination of the optimal tilt angle and optimal intervals based on forecasting model," IET Renewable Power Generation, vol. 11, no. 10, pp. 1261-1267, 2017, doi: 10.1049/iet-rpg.2016.1033.

[11] A. Kurniawan and E. Shintaku, "Determining the optimal inclination and orientation angles of solar panels installed on ship," International Journal of Renewable Energy Research, vol. 10, no. 1, pp. 45-53, 2020.

[12] M. Nfaoui and K. El-Hami, "Extracting the maximum energy from solar panels," Energy Reports, vol. 4, pp. 536545, 2018, doi: 10.1016/j.egyr.2018.05.002.

[13] M. R. B. Khan, J. Pasupuleti, J. Al-Fattah, and M. Tahmasebi, "Energy Management system for PV-battery microgrid based on model predictive control," Indonesian Journal of Electrical Engineering and Computer Science, vol. 15, no. 1, pp. 20-25, 2019. doi: 10.11591/ijeecs.v15.i1.pp20-26.

[14] O. N. Mensour, S. Bouaddi, B. Abnay, B. Hlimi, and A. Ihlal, "Mapping and estimation of monthly global solar irradiation in different zones in Souss-Massa area, Morocco, Using Artificial Neural Networks," International Journal of Photoenergy, 2017, doi: 10.1155/2017/8547437.

[15] C. Gurlek and M. Sahin, "Estimation of the global solar radiation with the artificial neural networks for the city of Sivas," European Mechanical Science, vol. 2, no. 2, pp. 46-51, 2018, doi: 10.26701/ems.359681.

[16] J. Almorox and C. Hontoria, "Global solar radiation estimation using sunshine duration in Spain," Energy Conversion and Management, vol. 45, no. 9-10, pp. 1529-1535, 2004, doi: 10.1016/j.enconman.2003.08.022.

[17] K. Bouchouicha, N. Bailek, M. E. S. Mahmoud, J. A. Alonso, A. Slimani, and Abdallah Djaafari, "Estimation of monthly average daily global solar radiation using meteorological-based models in Adrar, Algeria," Applied Solar Energy, vol. 54, no. 6, pp. 448-455, 2018, doi: 10.3103/S0003701X1806004X.

[18] A. Koca, H. F. Oztop, Y. Varol, and G. O. Koca, "Estimation of solar radiation using artificial neural networks with different input parameters for mediterranean region of anatolia in Turkey," Expert Systems with Applications, vol. 38, no. 7, pp. 8756-8762, 2011, doi: 10.1016/j.eswa.2011.01.085.

[19] V. Z. Antonopoulos, D. M. Papamichail, V. G. Aschonitis, and A. V. Antonopoulos, "Solar radiation estimation methods using ANN and empirical models," Computers and Electronics in Agriculture, vol. 160, pp. 160-167, 2019, doi: 10.1016/j.compag.2019.03.022. 
[20] S. Rehman and M. Mohandes, "Artificial neural network estimation of global solar radiation using air temperature and relative humidity," Energy Policy, vol. 36, no. 2, pp. 571-576, 2008, doi: 10.1016/j.enpol.2007.09.033.

[21] M. Alizamir, S. Kim, O. Kisi, and M. Zounemat-Kermani, "A Comparative study of several machine learning based non-linear regression methods in estimating solar radiation: Case studies of the USA and Turkey regions," Energy, vol. 197, 2020, doi: 10.1016/j.energy.2020.117239.

[22] R. U. K. Nadya, A. N. Ahmed, A. A. Borhana, N. A. Mardhiah, A. El-Shafie, and A. El-Shafie, "Daily predictions of solar radiation utilizing genetic programming techniques," Indonesian Journal of Electrical Engineering and Computer Science, vol. 19, no. 2, pp. 900-905, 2020, doi: 10.11591/ijeecs.v19.i2.pp900-905.

[23] S. A. Ghasempour and M. B. Menhaj, "A new genetic based algorithm for channel assignment problems," Computational Intelligence, Theory and Applications, pp. 85-91, 2006,doi: 10.1007/3-540-34783-6_10.

[24] J. Zeng and W. Qiao, "Short-term solar power prediction using a support vector machine," Renewable Energy, vol. 52, pp. 118-127, 2013, doi: 10.1016/j.renene.2012.10.009.

[25] S. Belaid and A. Mellit, "Prediction of daily and mean monthly global solar radiation using support vector machine in an arid climate," Energy Conversion and Management, vol. 118, pp. 105-118, 2016, doi: 10.1016/j.enconman.2016.03.082.

[26] M. Marzouq, H. El Fadili, Z. Lakhliai and K. Zenkouar, "A review of solar radiation prediction using artificial neural networks," 2017 International Conference on Wireless Technologies, Embedded and Intelligent Systems (WITS), 2017, pp. 1-6, doi: 10.1109/WITS.2017.7934658.

[27] T. Khatib, A. Mohamed, M. Mahmoud, and K. Sopian, "Modeling of daily solar energy on a horizontal surface for five main sites in Malaysia," International Journal of Green Energy, vol. 8, no. 8, pp. 795-819, 2011, doi: 10.1080/15435075.2011.602156.

[28] A. K. Yadav and S. S. Chandel, "Solar radiation prediction using artificial neural network techniques: A review," Renewable and Sustainable Energy Reviews, vol. 33, pp. 772-781, 2014, doi: 10.1016/j.rser.2013.08.055.

[29] A. Teke and H. B. Yildirim, "Estimating the monthly global solar radiation for Eastern Mediterranean region," Energy Conversion and Management, vol. 87, pp. 628-635, 2014, doi: 10.1016/j.enconman.2014.07.052.

[30] J. C. Lam, K. K. W. Wan, and L. Yang, "Solar radiation modelling using ANNs for different climates in China," Energy Conversion and Management, vol. 49, no. 5, pp. 1080-1090, 2008, doi: 10.1016/j.enconman.2007.09.021.

[31] D. H. W. Li, W. Chen, S. Li, and S. Lou, "Estimation of hourly global solar radiation using multivariate adaptive regression spline (MARS) - A case study of Hong Kong,” Energy, vol. 186, 2019, doi: 10.1016/j.energy.2019.115857.

[32] F. Albu, A. Mateescu, and N. Dumitriu, "Architecture selection for a multilayer feedforward network," in International Conference on Microelectronics and Computer Science, 1997, pp. 131-134.

[33] T. Czernichow, A. Germond, B. Dorizzi and P. Caire, "Improving recurrent network load forecasting," Proceedings of ICNN'95 - International Conference on Neural Networks, 1995, pp. 899-904 vol.2, doi: 10.1109/ICNN.1995.487538.

[34] A. K. Yadav, H. Malik, and S. S. Chandel, "Selection of most relevant input parameters using WEKA for artificial neural network based solar radiation prediction models," Renewable and Sustainable Energy Reviews, vol. 31, pp. 509-519, 2014, doi: 10.1016/j.rser.2013.12.008.

[35] A. Kurniawan and E. Shintaku, "Estimation of the monthly global, direct, and diffuse solar radiation in Japan using artificial neural network," International Journal of Machine Learning and Computing, vol. 10, no. 2, pp. 253-258, 2020, doi: 10.18178/ijmlc.2020.10.2.928.

[36] M. A. Behrang, E. Assareh, A. Ghanbarzadeh, and A. R. Noghrehabadi, "The potential of different artificial neural network (ANN) techniques in daily global solar radiation modeling based on meteorological data," Solar Energy, vol. 84, no. 8, pp. 1468-1480, 2010, doi: 10.1016/j.solener.2010.05.009.

[37] M. Marzouq, Z. Bounoua, A. Mechaqrane, H. E. Fadili, Z. Lakhliai, and K. Zenkouar, "ANN-based modelling and prediction of daily global solar irradiation using commonly measured meteorological parameters," IOP Conference Series: Earth and Environmental Science, vol. 161, no. 1, 2018, doi: 10.1088/1755-1315/161/1/012017. 